BULLETIN Bulletin hispanique

HISPANIQUE Université Michel de Montaigne Bordeaux

119-1 | 2017

Autorité et pouvoir dans le théâtre du Siècle d'Or

Verónica Sierra Blas, Cartas presas. La correspondencia carcelaria en la Guerra Civil y el Franquismo

Marcial Pons, Madrid, 2016

Jacques Issorel

\title{
OpenEdition
}

Journals

Édition électronique

URL : http://journals.openedition.org/bulletinhispanique/5005

DOI : 10.4000/bulletinhispanique.5005

ISBN : 979-10-300-0142-6

ISSN : $1775-3821$

Éditeur

Presses universitaires de Bordeaux

Édition imprimée

Date de publication : 15 juin 2017

Pagination : 394-396

ISBN : 979-10-300-0141-9

ISSN : 0007-4640

Référence électronique

Jacques Issorel, « Verónica Sierra Blas, Cartas presas. La correspondencia carcelaria en la Guerra Civil y el Franquismo », Bulletin hispanique [En ligne], 119-1 | 2017, mis en ligne le 15 juin 2017, consulté le 23 septembre 2020. URL : http://journals.openedition.org/bulletinhispanique/5005 ; DOI : https://doi.org/ 10.4000/bulletinhispanique.5005

Ce document a été généré automatiquement le 23 septembre 2020.

Tous droits réservés 


\section{Verónica Sierra Blas, Cartas presas. La correspondencia carcelaria en la Guerra Civil y el Franquismo}

Marcial Pons, Madrid, 2016

Jacques Issorel

\section{RÉFÉRENCE}

Verónica Sierra Blas, Cartas presas. La correspondencia carcelaria en la Guerra Civil y el Franquismo, Madrid, Marcial Pons, 2016, 361 p., 54 ill.

1 Comme pour son précédent ouvrage, Palabras huérfanas (Taurus 2009), consacré aux enfants victimes de la guerre civile et, pour 30000 d'entre eux, condamnés à l'exode et à l'exil, Verónica Sierra Blas a adopté un titre dont l'extrême concision exprime, davantage encore que le sous-titre (La correspondencia carcelaria en la Guerra Civil y el Franquismo), la tragédie vécue par des centaines de milliers de femmes et d'hommes dans les geôles de la République de 1931 à 1939 et dans celles du pouvoir franquiste de 1936 à la mort du général Franco. L'ouvrage se divise en quatre chapitres choisis, eux aussi, avec un sens aigu de la formule («I. Escrito en prisión»; «II. ¿Cartas cautivas?»; «III. Suplicar o morir »; « IV. En capilla »). Le prologue et l'épilogue, outre le rôle qui leur est généralement dévolu, pourraient être détachés de l'ensemble et constituer chacun un texte indépendant, en raison de leur richesse et de leur densité.

2 Ces «Lettres prisonnières » nous parlent de celles que les reclus envoyaient à leurs familles, de celles que ces dernières leur faisaient parvenir, mais aussi de tous les textes écrits qui conditionnaient la vie en prison: documents administratifs, «memorias impuestas» (p.56), textes clandestins (pamphlets, journaux), graffiti, avals, dénonciations, suppliques, journaux intimes. C'est à partir d'un ensemble de 1500 lettres et de nombreux documents officiels ou personnels que Verónica Sierra Blas a bâti ce livre dont on ne peut achever la lecture sans se souvenir de ce que Georges Duby 
disait à ses étudiants, futurs professeurs d'histoire: "Et surtout, quoi que vous enseigniez, n'oubliez jamais l'immense peine des hommes ». Sierra Blas constate que si, malgré l'état "tercermundista de los archivos carcelarios» (p. 34), on est bien renseigné sur le fonctionnement interne des prisons, la seule source pour savoir ce que «sintieron, pensaron o soñaron ", les prisonniers politiques de l'un et l'autre bord, nous est fournie par les lettres et les autres productions écrites citées plus haut. Pour parvenir aux familles ou pour être remises aux prisonniers, les lettres devaient franchir le terrible obstacle de la censure (p. 108). Aucun écart n'était toléré sous peine de destruction des envois. Aussi les plus téméraires écrivaient-ils quelquefois des messages habilement chiffrés, cachaient-ils un mince billet dans la doublure d'un vêtement ou subornaientils les gardiens. Outre le lien affectif qu'elle tissait, l'écriture représentait «una estrategia de resistencia, un medio clave de supervivencia y una ventana abierta al mundo» (p.98), tandis que pour l'administration pénitentiaire, les lettres et les autres productions écrites des prisonniers étaient une source précieuse d'informations et le moyen d'exercer sur eux chantages et pressions, et un motif pour leur infliger des sanctions (p. 110).

3 Autant que la censure, l'autocensure à laquelle s'astreignaient les détenus et leurs familles rendait les lettres des uns et des autres étrangement semblables : on donnait des nouvelles de sa santé, on se rassurait mutuellement, on exprimait son affection (p. 133). La lecture et les relectures des messages des uns et des autres constituaient une thérapie contre la solitude et la douleur de la séparation. Elles aidaient à vaincre la peur et à ne pas s'abandonner au désespoir : "sin cartas, écrit Verónica Sierra Blas, se hacía imposible resistir el encierro » (p. 44). Les lectures communautaires dans les cellules et au sein des familles, ajoutées aux échanges de lettres, créaient "una amplia red de corresponsales, cuya unión provocaba la asunción de un discurso polifónico» (p. 152), selon l'heureuse expression de l'auteur, qui offre aux pages 140-145 une magistrale analyse de la lettre écrite par Encarnación Toca Blanco à ses deux fils détenus à Santoña. Une large place est faite dans le livre aux « cartas de súplica » (p. 155-208), que les prisonniers adressaient à l'administration pénitentiaire et quelquefois à Franco, à Carmen Polo et même à leur fille, tantôt pour clamer leur innocence, tantôt pour demander de meilleures conditions de détention, des vêtements, des soins médicaux ou tout simplement... une paire d'espadrilles, comme le fit José María de Cos Oreña en août 1937, afin de pouvoir exercer la tâche de jardinier de la prison (p. 180). De telles lettres étaient pour le pouvoir franquiste le moyen de soumettre et d'humilier les détenus, qui devaient commencer leurs requêtes par des formules comme "Suplico de su bondadoso corazón... » (p. 164 sq.) et conclure en souhaitant longue vie au caudillo.

4 La partie la plus bouleversante du livre est celle consacrée aux "Cartas en capilla " (p. 209-299), c'est-à-dire les lettres écrites par les condamnés à mort, quelques heures avant leur exécution. Beaucoup de ces « lettres de mourants qui ne parlent que de vie » (J.J. Goldman, cité p. 215) n'arrivèrent jamais à leurs destinataires. Saisies par les autorités dont elles dénonçaient les mauvais traitements et l'iniquité, elles furent souvent détruites par les familles dans la crainte d'une possible répression. Beaucoup furent transmises aux proches par les prêtres chargés d'assister les condamnés. Revenant sur les réformes introduites par Victoria Kent en 1931, le pouvoir franquiste rendit en effet obligatoire l'« 'asistencia espiritual' a los reos » (p. 259). La confession et la communion étant des « requisitos imprescindibles para poder conseguir papel y pluma con los que escribir por última vez a sus seres queridos" (ibid.), nombreux furent ceux qui acceptèrent de recevoir à leur corps défendant ces deux sacrements, d'autres le firent 
par conviction. Verónica Sierra Blas explique bien comment ces "cartas en capilla ", à l'origine textes intimes et privés, devinrent des outils de lutte politique et des «objetos de propaganda eficaz y denuncia feroz» (p. 275). Ainsi les lettres des "Trece Rosas", fusillées le 5 août 1939 à Madrid, et, en particulier, celle de Blanca Brisac à son fils Enrique, reproduite en fac-similé (p. 271) ; ainsi celles adressées à leurs familles par les cinquante et un religieux clarétains fusillés à Barbastro en août 1936, lesquelles constituèrent des preuves décisives en vue de leur béatification par Jean-Paul II en 1992 (p. $277 s q)$.

5 Avec Cartas presas, où elle fait preuve d'une rigueur scientifique sans faille - laquelle n'exclut pas une évidente empathie pour les femmes et les hommes des deux camps à qui elle rend hommage -, Verónica Sierra Blas nous offre un travail de recherche qui découvre un large pan, peu ou mal connu, de l'histoire de l'Espagne et des Espagnols. Parfaitement construit, écrit dans une langue castillane élégante, riche et claire, abondamment illustré, imprimé avec soin sur un papier légèrement crème, ce livre est tout simplement un grand livre.

\section{AUTEURS}

JACQUES ISSOREL

Université de Perpignan 